it seems certain that if the limb were smooth the moon's place would be determined with considerably greater accuracy than that with which it is at present computed in the Nautical Almanac. Whatever the limb-effects may be, the accuracy should be higher than that which results from six thousand ordinary occultations, since the timing is considerably better than is possible with visual methods, while all effects due to personality, systematic time-differences between stations, and real changes of libration are eliminated. If the method works out as well as is hoped, it will probably be used for long-range geodetic purposes; the accuracy will then be more severely limited by our ignorance of the moon's limb, since considerable changes in the libration are inseparable from a long shadow-path. However, the accuracy should still be considerably greater than can be obtained, for the same purpose, by merely timing the instants of contact, since in that case all the emphasis is on some one point of the limb at each contact; a chance error at that point can cause a large error in the time.

\section{Frozen Foods Consultative Group}

To ensure the fullest co-operation and collaboration between the various research organisations engaged in the field of food, and also that inquirers will be directed to the best sources of information, the Frozen Foods Consultative Group was set up last year. It consists of representatives of research organisations, official and semi-official, under the chairmanship of the director of food investigation, Dr. Franklin Kidd. The objects of the Group are in the main the exchange of information on research investigations in progress on the preservation of food by quick-freezing processes so as to prevent overlapping and to discover gaps in research programmes. The terms of reference are : $(a)$ to table and discuss the results of investigations into new developments in methods of preserving food by freezing; $(b)$ to consider the planning of further investigations (each organisation to retain its own independence and the responsibility for its own programme); (c) to maintain contact between investigators in such fields as packaging and engineering which bear on preservation by freezing; $(d)$ to direct inquirers in industry to the best sources of information. The following research organisations and stations are represented: Low Temperature Research Station, Torry Research Station and Ditton Laboratory (all of the Department of Scientific and Industrial Research); Scien. tific Adviser's Division, Ministry of Food ; British Food Manufacturing Industries Research Association; Printing, Packaging and Allied Trades Research Association; British Baking Industries Research Association; Fruit and Vegetable Preservation Research Station, Chipping Campden. The Group has power to invite to its meetings representatives of other organisations such as the Refrigerated Cargo Research Council, the Institute of Refrigeration and the Food Manufacturers Federation. The secretary of the Group is Mr. P. R. P. Claridge, Food Investigation Organisation, Lloyds Bank Chambers, Hobson Street, Cambridge.

\section{Petroleum Films Bureau}

IT may not be generally known that there exists in London an organisation specializing in circulation (free of charge to responsible bodies such as educational and Service authorities) of $35 \mathrm{~mm}$. and $16 \mathrm{~mm}$. sound and silent documentary instructional films. The
August catalogue has reached us from the Petroleum Films Bureau, 46 St. James' Place, London, S.W.1, sponsors of this scheme, from which it is clear that the range of subjects covered is not limited to varying aspects of the oil industry. Titles of general interest include the microscope, microscopy of opaque objects, hydraulics and hospital service. "How Oil is Produced and Refined" is covered by fifteen different reels giving a total of more than three hours showing. Other sections deal with automobile engineering and road safety for children. Short synopses of each film are available; also lantern slides, with appropriate lecture notes, on the subject "About Oil" can be borrowed to illustrate the early history of oil, its nature, origin, production, refining and transportation. This is a valuable scheme, capable of great expansion and certain of support in lecture theatre, classroom, drill hall and, presumably, the home.

\section{Fertilizer Manufacture in East Africa}

A sCIENTIFIC mission from East Africa is at present on a short visit to the United States to study the methods employed by the Tennessee Valley Authority in the manufacture of fertilizers. Large deposits of rock phosphates are known to exist in Uganda, and it is expected that the knowledge gained from this visit can be applied to the exploitation of these deposits when hydro-electric power becomes available from the Owen Falls scheme. The members of the mission are: Dr. A. J. V. Underwood, industrial consultant in London to the East Africa High Com. mission; Mr. H. B. Stent, acting chairman of the East African Industrial Research Board; Dr. K. A. Davies, director of the Geological Survey, Uganda; and Mr. C. R. Westlake, chairman of the Uganda Electricity Board.

\section{Life-Histories of Birds}

The United States National Museum has issued a number of bulletins dealing with the life-histories of various North American birds. The latest addition to the series covers the nuthatches, wrens, thrashers and their allies, and is a painstaking work. $\mathrm{Mr}$. Burt, the author, says that he has endeavoured to give as full a life-history as possible of the best-known sub-species of each species, and has written more briefly of the related sub-species, by this method avoiding repetition and duplication. He has amassed much information which is presented in a clear and readable manner, the volume being illustrated by a large number of photographs, mostly excellent ones, the last, of a sage thrasher, being a particularly successful picture.

\section{Edward Livingston Trudeau (1848-1915)}

When he was a student at the New York College of Physicians and Surgeons, Edward Livingston Trudeau, who was born on October 5, 1848, was taught to regard tuberculosis as an incurable disease. When, therefore, the celebrated physician Edward G. Janeway in 1873 diagnosed extensive tuberculosis in his left lung, his patient, who had recently graduated and married and whose brother had died of the same disease, felt he was under sentence of death and gave up his practice to spend his last days in the Adirondack Mountains. To his and everyone else's surprise he recovered, and in 1884 established the open-air Adirondack Cottage Sanitarium-the first in the United States. In the isolation of a primitive forest, badly crippled and single-handed, Trudeau preached and practised the gospel of fresh air and extolled 